\title{
Nucleophilic Additions to Coordinated 1,10-phenanthroline: Intramolecular, Intermolecular, Reversible and Irreversible
}

\author{
Rebeca Arévalo, ${ }^{[\mathrm{a}]} \mathrm{M}$. Isabel Menéndez, ${ }^{[\mathrm{b}]}$ Ramón López, ${ }^{[\mathrm{b}]}$ Isabel Merino, ${ }^{[\mathrm{c}]}$ Lucía Riera, ${ }^{[\mathrm{d}]}$ and Julio \\ Pérez ${ }^{*[a, d]}$
}

\begin{abstract}
KN}\left(\mathrm{SiMe}_{3}\right)_{2}$ reacts with $\left[\operatorname{Re}(\mathrm{CO})_{3}(\right.$ phen $\left.)\left(\mathrm{PMe}_{3}\right)\right] \mathrm{OTf}$ via reversible addition to the phen ligand and irreversible deprotonation of the $\mathrm{PMe}_{3}$ ligand followed by intramolecular attack to phen by the deprotonated phosphane, while MeLi irreversibly adds to phen. The addition of MeLi has been shown to be intermolecular, unlike previously known nucleophilic additions to pyridines.
\end{abstract}

The relevance of pyridine rings is partly due to their prevalence as donors in transition metal (TM) chemistry. 2,2'-bipyridine (bipy) and 1,10-phenanthroline (phen) are the most extensively employed among these ligands. Some families of their TM complexes, rhenium carbonyls being a prime example, are promising tools in several areas of contemporary research. ${ }^{[1]}$ However, the organic chemistry of TM-coordinated bipy and phen remains virtually unexplored. ${ }^{[2]}$ Additions of main group metal alkyls to free pyridines, including bipy and phen, are well known reactions ${ }^{[3]}$ Coordination to a Lewis-acidic metal center could be expected to enhance the electrophilic character of pyridine donors However, examples of nucleophilic addition to the pyridyl rings of TM-coordinated bipy, phen or other pyridine-containing ligands are scarce ${ }^{[4,5]}$ despite a long-time interest in one such reaction, namely, covalent hydration. ${ }^{[6]}$ Intramolecular additions have been demonstrated in which a nucleophilic group is generated by the reaction of one of the ligands with an external reagent, ${ }^{[7]}$ but a truly intermolecular addition remains elusive. Here we report, among other reactions, the first examples.

Addition of $\mathrm{KN}\left(\mathrm{SiMe}_{3}\right)_{2}$ to a yellow $\mathrm{THF}$ solution of $\left[\operatorname{Re}(\mathrm{CO})_{3}(\right.$ phen $\left.)\left(\mathrm{PMe}_{3}\right)\right] \mathrm{OTf}(1)$ at $-78^{\circ} \mathrm{C}$ (IR vCO: 2034,1945 and $1920 \mathrm{~cm}^{-1}$ ) immediately produced a purple solution with $v C O$ bands at 2014, 1918 and $1888 \mathrm{~cm}^{-1}$, diagnostic of a neutral fac$\operatorname{Re}(\mathrm{CO})_{3}$ complex. After 1 hour at room temperature, the solution darkened, its IR spectrum showed bands at 2010, 1916 and 1888 $\mathrm{cm}^{-1}$, and its NMR revealed a single organometallic product, $\mathbf{2}$,

[a] R. Arévalo, Dr. J. Pérez

Departamento de Química Orgánica e Inorgánica

Universidad de Oviedo

Julián Clavería 8, 33006 Oviedo (Spain)

E-mail: japm@uniovi.es

[b] Dr. M. I. Menéndez, Dr. R. López

Departamento de Química Física y Analítica

Universidad de Oviedo

Julián Clavería 8, 33006 Oviedo (Spain)

[c] Dr. I. Merino

Unidad de Resonancia Magnética Nuclear

Servicios Científico-Técnicos de la Universidad de Oviedo

Fernando Bongera s/n, 33006 Oviedo (Spain)

[d] Dr. J. Pérez, Dr. L. Riera

Centro de Investigación en Nanomateriales y Nanotecnología

(CINN), CSIC-Universidad de Oviedo-Principado de Asturias Avda. de la Vega 4-6, 33940 El Entrego (Spain)

Supporting information for this article is given via a link at the end of the document: Experimental and computational details and data (PDF) and crystallographic information for compounds 2 and 4M-C2 (CIF) which could be isolated as red crystals in $46 \%$ yield. The ${ }^{1} \mathrm{H}$ and ${ }^{13} \mathrm{C}$ NMR spectra of 2 were assigned on the basis of $2 \mathrm{D}$ COSY, ${ }^{1} \mathrm{H}^{13} \mathrm{C}$ HSQC and ${ }^{1} \mathrm{H}^{13} \mathrm{C}$ HMBC experiments and showed the dearomatization of one pyridyl ring. ${ }^{1} \mathrm{H}$ NMR signals at 2.10 and $1.83 \mathrm{ppm}\left(\mathrm{THF}-\mathrm{d}_{8}\right)$ are assigned to the diasterotopic $\mathrm{H}$ atoms of a $\mathrm{P}-\mathrm{CH}_{2}$ group. Their couplings of 9.7 and $5.9 \mathrm{~Hz}$ respectively with the $4.63 \mathrm{ppm}$ signal of the $\mathrm{C} 2-\mathrm{H}$ group of the dearomatized ring indicate intramolecular attack on the phen C2(9) position after $\mathrm{PMe}_{3}$ deprotonation, as depicted in Scheme 1. The nitrogen atoms of 2 occur at 97.7 (dearomatized ring) and $233.2 \mathrm{ppm}$ in the ${ }^{15} \mathrm{~N}$ NMR spectrum (obtained through ${ }^{1} \mathrm{H}^{-}{ }^{15} \mathrm{~N}$ HMBC in THF$\mathrm{d}_{8}$; for $1, \delta\left({ }^{15} \mathrm{~N} \mathrm{NMR}\right)=226.5 \mathrm{ppm}$ in THF- $\left.\mathrm{d}_{8}\right)$, reflecting their very different natures. In contrast with its bipy analog, ${ }^{[7 a]}$ which could not be crystallized due to its low stability, solutions of $\mathbf{2}$ are stable for several days at room temperature, and its crystals are shelfstable for at least one month. The X-ray structure of 2 (Figure 1), confirmed the connectivity shown in Scheme 1 and the loss of planarity of the $\mathrm{N} 1$ ring: alternate single or double $\mathrm{C}-\mathrm{C}$ bond distances (e. g. C3-C4= 1.328(8) $\AA$ and C4-C12=1.449(7) $\AA$ ) contrast with the intermediate values in the aromatic N10 ring (shortest: C7-C8 $=1.360(7) \AA$, longest: C14-C7=1.409(7) $\AA$ ). The tetrahedral geometry around $\mathrm{C} 2$ (e. g. the N1-C2-C15 angle is 107.1(4) $\left.{ }^{\circ}\right)$ agrees with its $\delta\left({ }^{13} \mathrm{C}\right)$ NMR at $64.9 \mathrm{ppm}$. The sum of the angles around $\mathrm{N} 1,349.1(4)^{\circ}$, shows a

(a)

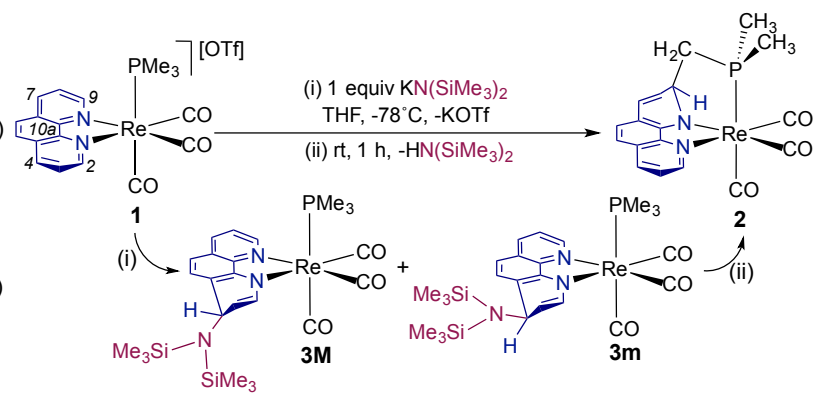

Scheme 1. Additions to the phen ligand of 1: (a) Intramolecular attack of a deprotonated $\mathrm{P}_{-} \mathrm{CH}_{3}$ group on $\mathrm{C} 2(9)$, and (b) intermolecular attack of $\mathrm{KN}\left(\mathrm{SiMe}_{3}\right)_{2}$ on $\mathrm{C} 4(7)$
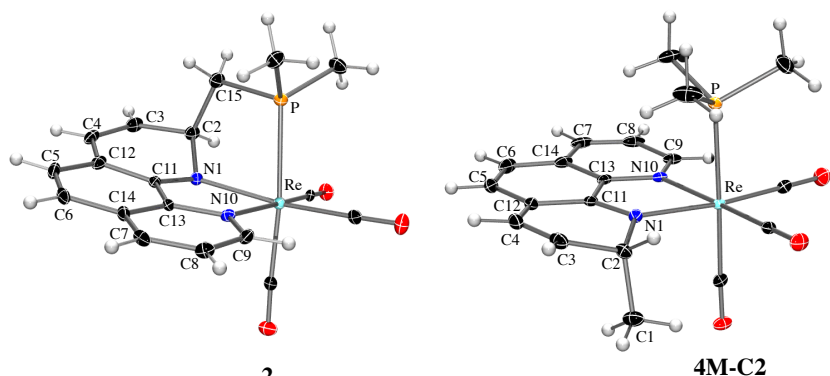

Figure 1. Thermal ellipsoid (30\% probability) plots of $\mathbf{2}$ and $\mathbf{4 M - C 2 .}$ 
rare pyramidal -rather than planar- geometry for the amido group. ${ }^{[8]}$

Low temperature NMR monitoring of the reaction of 1 with $\mathrm{KN}\left(\mathrm{SiMe}_{3}\right)_{2}$ revealed the presence of two intermediates, $\mathbf{3} \mathbf{M}$ and $3 \mathbf{m}$, in a 17:1 ratio, both with intact $\mathrm{PMe}_{3}$ ligands and one dearomatized pyridine ring, resulting from amide attack to the $\mathrm{C} 4$ (7) position of phen (from ${ }^{1} \mathrm{H}-{ }^{29} \mathrm{Si} \mathrm{HMQC}, \mathrm{COSY},{ }^{1} \mathrm{H}_{-}{ }^{13} \mathrm{C} \mathrm{HMBC}$ and ${ }^{1} \mathrm{H}^{15} \mathrm{~N}$ HMBC NMR). ${ }^{[9]} \mathbf{3 M}$ and $3 \mathrm{~m}$ differ in the relative orientation of the $\mathrm{N}\left(\mathrm{SiMe}_{3}\right)_{2}$ group (shown by the 2D NOESY), 3M corresponding to the attack to the less hindered side of phen, anti with respect to $\mathrm{PMe}_{3}$ (see Scheme 1). The ortho carbons of pyridines are the main target of nucleophilic attack in the Chichibabin ${ }^{[10]}$ and related reactions. ${ }^{[11]}$ The failure to detect such products in the reaction of 1 with $\mathrm{KN}\left(\mathrm{SiMe}_{3}\right)_{2}$ is attributed to the metal fragment blocking the approach of the very bulky amide nucleophile.

A ${ }^{1} \mathrm{H}$ DOSY experiment ${ }^{[12]}$ of a reaction mixture containing 2, 3M and $3 \mathrm{~m}$ at $298 \mathrm{~K}$ in toluene- $\mathrm{d}_{8}$ afforded diffusion coefficients for $3 \mathrm{M}$ and $\mathbf{2}$ consistent with their proposed formulations (see Figures S46 and S47 of the SI). Two mechanisms can be envisaged for the evolution of the $\mathbf{3 M}, 3 \mathrm{~m}$ mixture toward 2 : amide dissociation followed by $\mathrm{PMe}_{3}$ deprotonation by free amide, or an inner-sphere concerted deprotonation of $\mathrm{PMe}_{3}$ by the amide, conceivable at least for $\mathbf{3 m}$, in which amide and $\mathrm{PMe}_{3}$ groups are on the same side of phen. The long distance between the amide nitrogen and the phosphane hydrogens $(5.118 \AA$ ) in a computational model of $3 \mathrm{~m}$ militates against the latter mechanism. DFT calculations (vide infra) support that the reaction of 1 with $\mathrm{KN}\left(\mathrm{SiMe}_{3}\right)_{2}$ is reversible (pyridyl rearomatization must provide part of the driving force for amide dissociation), and that $\mathrm{PMe}_{3}$ is deprotonated by free amide. Reversible, non-productive formation of dearomatized adducts is common as the first step of the reactions of nucleophiles with electron-poor arenes, such as nitroarenes. ${ }^{[13]}$

Reaction of MeLi with 1 in toluene produced a green solution from which, after 5 days, $\mathbf{4 M - C 2}$ was isolated in 38\% yield (see Scheme 2). 2D COSY and ${ }^{1} \mathrm{H}-{ }^{15} \mathrm{~N}$ HMBC NMR showed that $4 \mathrm{M}$ C2 results from methyl addition to C2(phen), and 2D NOESY establishes the position of the methyl group on the side of phen opposite to $\mathrm{PMe}_{3}$. The structure was confirmed by X-ray diffraction (see Figure 1). The geometry about the amido-like N1 atom is planar, as most often found in TM-complexes, including rhenium carbonyls. ${ }^{[8]} \mathbf{4 M - C 2}$ is an $18 \mathrm{e}^{-}$complex if a single Re-N1 bond is counted, so the amido lone pair is either delocalized through the aryl ring, donated to the $\mathrm{CO}$ ligands through the metal $\mathrm{d} \pi$ orbitals,${ }^{[14]}$ or both. Hence, the pyramidal-at-N1 geometry in 2 is attributed to its constrained cyclic geometry. NMR showed the initial green solution to consist of four products
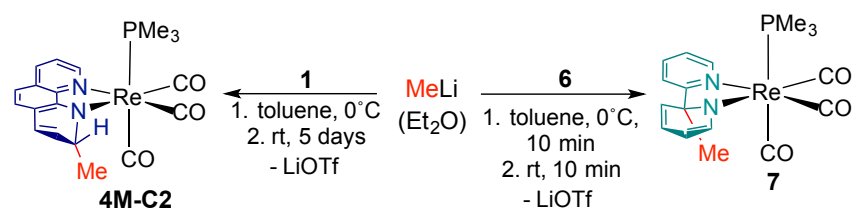

Scheme 2. Intermolecular attack of MeLi to C2 of phen and bipy in 1 and 6 respectively.
(4M-C2, 4M-C4, 4m-C2 and $4 \mathrm{~m}-\mathrm{C} 4$ in a 1.0:0.7:0.2:0.2 ratio by ${ }^{1} \mathrm{H}$ and ${ }^{31} \mathrm{P}$ NMR integration 1 hour after the addition of MeLi and quick workup, see Figures S56 and S57), and indicated a composition for $\mathbf{4 M - C 4}$ similar to that found for $\mathbf{4 M - C 2}$, but with the methyl group on $\mathrm{C} 4$ (phen). Although the stereochemistry at C4(phen) in 4M-C4 could not be elucidated, methyl addition to the less hindered phen side (opposite to $\mathrm{PMe}_{3}$ ) is proposed. For $4 \mathrm{~m}$ C2 and 4m-C4 most ${ }^{1} \mathrm{H}$ NMR signals were obscured by the signals of the major products, but those of the phen-bonded methyl groups, which could be distinctly observed, showed ${ }^{1} \mathrm{H}-{ }^{13} \mathrm{C}$ HMBC cross-peaks identical to those of $4 \mathrm{M}-\mathrm{C2}$ and $4 \mathrm{M}-\mathrm{C} 4$ respectively. Hence, the same connectivity, but methyl groups on the $\mathrm{PMe}_{3}$ side of phen are proposed for $\mathbf{4 m}-\mathrm{C} 2$ and $\mathbf{4 m}-\mathrm{C} 4$ (see Scheme S1). A ${ }^{1} \mathrm{H}$ DOSY NMR experiment showed that the four products display comparable diffusion coefficients, supporting their formulation as isomers (see Figures S68 and S69). The concentration of the four products in the green solution decreased over time (by ${ }^{1} \mathrm{H}$ NMR integration against $\mathrm{C}_{6} \mathrm{Me}_{6}$ as internal standard, see Figure $S 67)^{[15]}$ and a brown material precipitated, consisting of several species containing aromatic phenanthrolines. The precipitate-forming reaction is proposed to be an oxidation, perhaps by traces of dissolved $\mathrm{O}_{2}$. Supporting this proposal, $4 \mathrm{~m}$ $\mathrm{C2}$ and $\mathbf{4 m - C 4}$, with the $\mathrm{H}$ atom which would be abstracted on the more accessible phen face (opposite to $\mathrm{PMe}_{3}$ ), are the less stable isomers. Dearomatized products resulting from nucleophilic addition to pyridine rings tend to re-aromatize, most often by an elimination step, so that the overall reaction is a nucleophilic aromatic substitution. ${ }^{[16]}$ In the absence of a good leaving group, hydride can be abstracted by typical oxidants or be transferred to hydride acceptors such as carbonyl groups. ${ }^{[17]}$ The different rate at which the four products of MeLi addition to 1 decay shows that they do not interconvert, in contrast with several bis(imino)pyridine metal complexes, in which alkyl migration has been established.

In the reactions of bipy, phen and other conjugated diimines with main group metal nucleophiles (MY), following the initial formation of a diimine-MY adduct, a single electron transfer from MY to a low energy, empty molecular orbital of the diimine weakens the $\mathrm{M}-\mathrm{Y}$ bond, facilitating its homolysis to generate a $\mathrm{Y}$. radical, which eventually adds to the ring. ${ }^{[18]}$ For the reactions of MY with transition metal complexes in which bipy and phen form robust, non-labile chelates, ${ }^{[19]}$ such a low-energy ${ }^{[20]}$ radical pathway is not available.

The mechanism of most dearomatizations of TM-bonded pyridine rings (including the few examples involving bipy or phen) consists of an initial nucleophilic attack to the metal followed by an intramolecular migration of the nucleophile to the ring ${ }^{[5]}$ reminiscent of the main group chemistry mentioned above. A direct addition to the coordinated pyridine ring has never been demonstrated, and one can wonder if TM fragments do not in fact sterically impede the approach of the nucleophile to the kinetically favored 2(6) position. Moreover, it has been noted that electronically, metal fragments capable of back-donation could deactivate pyridine rings towards nucleophilic attack. ${ }^{[21]}$ Could the reaction of 1 with MeLi proceed by $\mathrm{PMe}_{3}$ displacement to form $\left[\operatorname{Re}(\right.$ phen $\left.)(\mathrm{CO})_{3}(\mathrm{Me})\right](5)$, followed by intramolecular methyl migration from $\mathrm{Re}$ to phen, aided by $\mathrm{PMe}_{3}$ re-coordination? Treatment of independently synthesized $\mathbf{5}$ with 1 equivalent of 
$\mathrm{PMe}_{3}$ in toluene afforded, after 1 hour at room temperature, unreacted $\mathbf{5}$, ruling out this hypothesis.

Part of the driving force in previously known dearomatizations of coordinated pyridyl rings is provided by the strengthening of the $\mathrm{N}-\mathrm{M}$ bond, due to the $\pi$-donation from the created amido group to empty metal orbitals. ${ }^{[\mathrm{b}, 4 \mathrm{~d}, 5 \mathrm{~d}]} \mathrm{A}$ similar effect could be present in our complexes due to the presence of strongly $\pi$-accepting carbonyl co-ligands, to which electron density from the amido group can be transferred through the metal $\mathrm{d} \pi$ orbitals. ${ }^{[14]}$

Aiming to obtain an approximate understanding of the reactions (their study is complicated by the formation of salt byproducts, vide infra), and in particular of their reversible $\left(\mathrm{KN}\left(\mathrm{SiMe}_{3}\right)_{2}\right)$ and irreversible (MeLi) character, the additions to 1 have been investigated by DFT (see Figure 2). In the reaction with $\mathrm{KN}\left(\mathrm{SiMe}_{3}\right)_{2}, 3 \mathbf{M ~}\left(-2.6 \mathrm{kcal} \cdot \mathrm{mol}^{-1}\right)$ and $3 \mathrm{~m}\left(0.2 \mathrm{kcal} \cdot \mathrm{mol}^{-1}\right)$ form with no barriers. Following $\mathrm{PMe}_{3}$ deprotonation, intramolecular additions to $\mathrm{C} 10 \mathrm{a}$ or to $\mathrm{C} 2$, producing $2^{*}\left(-9.5 \mathrm{kcal} \cdot \mathrm{mol}^{-1}\right)$ or $2(-$ $\left.22.2 \mathrm{kcal} \cdot \mathrm{mol}^{-1}\right)$ respectively, present barriers of 4.1 and 3.9 $\mathrm{kcal} \cdot \mathrm{mol}^{-1}$. Hence, intermolecular addition is favored at low T. At higher $\mathrm{T}$, free amide, regenerated from $3 \mathrm{M}$ and $3 \mathrm{~m}$, deprotonates $\mathrm{PMe}_{3}$ and the small barriers for intramolecular addition can be surmounted, ultimately leading to the most stable product $\mathbf{2}$. The KOTf product has been modeled as a molecular species without additional donors coordinated to the potassium cation. Preliminary calculations show that including the binding of $\mathrm{K}^{+}$by several THF molecules leads to a lower energy. If, under the reaction conditions, KOTf (or part of it) is a solid, its lattice energy will also lower the energy. Therefore, the very small, yet positive, energy value computed for $3 \mathrm{~m}$ is not a concern.

For the reaction with $\mathrm{MeLi}$, the barrier to deprotonation (16.2 $\mathrm{kcal} \cdot \mathrm{mol}^{-1}$ ) is significantly higher than those for the irreversible formation of the products of intermolecular addition $\left(9.6 \mathrm{kcal} \cdot \mathrm{mol}^{-}\right.$ ${ }^{1}$ for $\mathbf{4 M}-\mathbf{C} 4$ and $11.8 \mathrm{kcal} \cdot \mathrm{mol}^{-1}$ for $\mathbf{4 M}-\mathbf{C 2}$ ), explaining why the latter are the observed products.

Yellow $\left[\operatorname{Re}(\right.$ bipy $\left.)(\mathrm{CO})_{3} \mathrm{PMe}_{3}\right] \mathrm{OTf}(6)^{[7 \mathrm{a}]}\left(2034,1938,1915 \mathrm{~cm}^{-1}\right.$ in toluene) reacts with $\mathrm{MeLi}$ in toluene affording a red solution with IR bands at 2012, 1917 and $1885 \mathrm{~cm}^{-1}$ containing a single product (as judged by ${ }^{1} \mathrm{H}$ and ${ }^{31} \mathrm{P} \mathrm{NMR}$ ), 7, with an asymmetric dearomatized bipy ligand and an intact $\mathrm{PMe}_{3}$ ligand. COSY, ${ }^{1} \mathrm{H}-$ ${ }^{13} \mathrm{C}$ HMBC, ${ }^{1} \mathrm{H}-{ }^{13} \mathrm{C}$ HSQC and ${ }^{1} \mathrm{H}-{ }^{15} \mathrm{~N}$ HMBC experiments showed cross-peaks consistent with the methyl group $(3 \mathrm{H}$ singlet at 1.41 ppm) being bonded to C2(2') of bipy (see Scheme

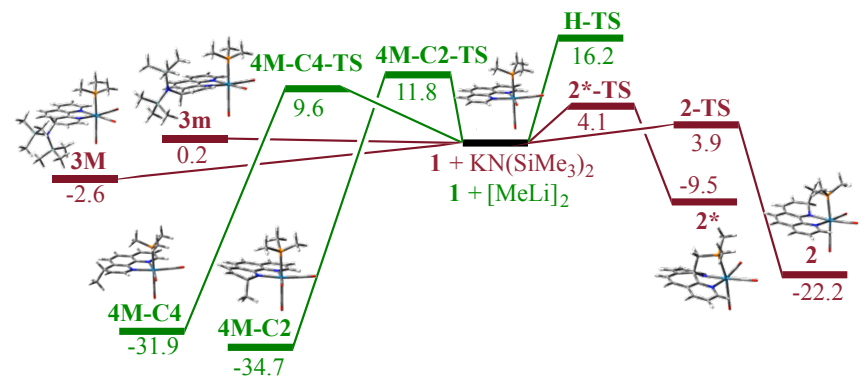

Figure 2. $P C M-B 3 L Y P / 6-31+G(d)$ (LANL2DZ for Re) Gibbs energy profiles $\left(\mathrm{kcal} \cdot \mathrm{mol}^{-1}\right)$ for the reactions of 1 with $\mathrm{KN}\left(\mathrm{SiMe}_{3}\right)_{2}$ in $\mathrm{THF}$ (red line) and $\left[\mathrm{MeLi}_{2}{ }_{2}^{[22]}\right.$ in toluene (green line). $2^{*}$ is the product of the intramolecular attack by the deprotonated group on phen $\mathrm{C} 10 \mathrm{a}$. Energies are referred to the reactants. See pages S100-S112 for absolute energy values and optimized structures.
2). No cross-peaks between that methyl group and $\mathrm{PMe}_{3}$ were found in the 2D NOESY spectrum, hinting that the methyl group is on the bipy face opposite to $\mathrm{PMe}_{3}$, as expected on steric grounds.

In summary, the bulky, typically non-nucleophilic amide $\mathrm{KN}\left(\mathrm{SiMe}_{3}\right)_{2}{ }^{[23]}$ reversibly adds to $\mathrm{C} 4(7)$ of phen in $\left[\operatorname{Re}(\mathrm{CO})_{3}(\right.$ phen $\left.)\left(\mathrm{PMe}_{3}\right)\right] \mathrm{OTf}(1)$, yielding two diasteromers which evolve through $\mathrm{PMe}_{3}$ deprotonation by free amide, followed by intramolecular addition of the $\mathrm{P}-\mathrm{CH}_{2}$ group to $\mathrm{C} 2(9)$ of phen. MeLi irreversibly adds to $\mathrm{C} 2(9)$ and $\mathrm{C} 4(7)$ of phen in $\mathbf{1}$ in an intermolecular fashion. ${ }^{[2]}$ Addition of MeLi to $\left[\operatorname{Re}(\mathrm{CO})_{3}(\right.$ bipy $\left.)\left(\mathrm{PMe}_{3}\right)\right] \mathrm{OTf}(6)$ takes place exclusively on the quaternary $\mathrm{C} 2\left(2^{\prime}\right)$ position of bipy. ${ }^{[3 \mathrm{a}]}$ Therefore, rheniumcoordinated bipy and phen are significantly electrophilic and can undergo the addition of internal and external nucleophiles. Reactions as the ones reported here can provide access to unexplored types of complexes, but also open deactivation pathways of bipy- and phen-containing functional compounds, similar to those known for imine complexes, but previously unrecognized for bipy and phen. ${ }^{[25]}$

\section{Acknowledgements}

The authors thank MINECO and FEDER (grant CTQ2015-70231P) and Principado de Asturias (grant FC-15-GRUPIN14-103) for funding, and Ministerio de Educación for an FPU predoctoral fellowship (to R.A.).

Keywords: $\mathrm{N}$ ligands $\cdot$ Nucleophilic addition $\cdot$ Phenanthroline complexes $\cdot$ Pyridine dearomatization $\bullet$ Rhenium carbonyls

[1] a) S. Oh, J. R. Gallagher, J. T. Miller, Y. Surendranath, J. Am. Chem. Soc. 2016, 138, 1820-1823; b) K. K. -W. Lo, Acc. Chem. Res. 2015, 48, 2985-2995; c) L. M. Kiefer, J. T. King, K. J. Kubarych, Acc. Chem. Res. 2015, 48, 1123-1130; d) A. Zarkadoulas, E. Koutsouri, C. Kefalidi, C. A. Mitsopoulou, Coord. Chem. Rev. 2015, 304-305, 55-72; e) S. Sato, O. Ishitani, Coord. Chem. Rev. 2015, 282-283, 50-59; f) R. M. Spada, M. Cepeda-Plaza, M. L. Gómez, G. Günther, P. Jaque, N. Pizarro, R. E. Palacios, A. Vega, J. Phys. Chem. C 2015, 119, 10148-10159; g) W. -K. Chu, C. -C. Ko, K. -C. Chan, S. -M. Yiu, F. -L. Wong, C. -S. Lee, V. A. L. Roy, Chem. Mater. 2014, 26, 2544-2550; h) C. W. Machan, S. A. Chabolla, J. Yin, M. K. Gilson, F. A. Tezcan, C. P. Kubiak, J. Am. Chem. Soc. 2014, 136, 14598-14607; i) C. Bachmann, B. Probst, M. Guttentag, R. Alberto, Chem. Commun. 2014, 50, 6737-6739; j) A. Leonidova, G. Gasser, ACS Chem. Biol. 2014, 9, 2180-2193; k) A. E. Pierri, A. Pallaoro, G. Wu, P. C. Ford, J. Am. Chem. Soc. 2012, 134, 18197-18200; I) A. J. Morris, G. J. Meyer, E. Fujita, Acc. Chem. Res. 2009, 42, 1983-1994; m) A. Cannizzo, A. M. Blanco-Rodríguez, A. El Nahhas, J. Sebera, S. Zális, A. Jr. Vlcek, M. Chergui, J. Am. Chem. Soc. 2008, 130, 8967-8974; n) J. Rohacova, O. Ishitani, Chem. Sci. 2016, DOI: 10.1039/C6SC01913G.

[2] D. Tzalis, Y. Tor, Angew. Chem. Int. Ed. Engl. 1997, 36, 2666-2668.

[3] a) C. Weetman, M. S. Hill, M. F. Mahon, Polyhedron 2016, 103, 115-120; b) S. D. Robertson, A. R. Kennedy, J. J. Liggat, R. E. Mulvey, Chem. Commun. 2015, 51, 5452-5455; c) Y. Naganawa, T. Namba, T. Aoyama, K Shoji, H. Nishiyama, Chem. Commun. 2014, 50, 13224-13227; d) M. Schlosser, Top. Heterocycl. Chem. 2013, 31, 171-222; e) S. Jakobsen, M. Tilset, Tetrahedron Lett. 2011, 52, 3072-3074; f) O. Moudam, F. Ajamaa, A. Ekouaga, H. Mamlouk, U. Hahn, M. Holler, R. Welter and J. -F. Nierengarten, Eur. J. Org. Chem. 2007, 417-419; g) W. Clegg, L. 
Dunbar, L. Horsburgh, R. E. Mulvey, Angew. Chem. Int. Ed. 1996, 35 753-755; h) D. Barr, R. Snaith, R. E. Mulvey, D. Reed, Polyhedron 1988 7, 665-668; i) T. Kauffmann, J. König, A. Woltermann, Chem. Ber. 1976 109, 3864-3868; j) R. F. Francis, W. Davis, J. T. Wisener, J. Org. Chem. 1974, 39, 59-62; k) R. Levine, W. M. Kadunce, Chem. Commun. 1970, 921-922; I) R. A. Abramovitch, B. Vig, Can. J. Chem. 1963, 41, 1961 1965.

[4] a) S. Kundu, W. W. Brennessel, W. D. Jones, Inorg. Chem. 2011, 50, 9443-9453; b) J. Scott, S. Gambarotta, I. Korovkov, P. H. M. Budzelaar J. Am. Chem. Soc. 2005, 127, 13019-13029; c) H. Sugiyama, G. Aharonian, S. Gambarotta, G. P. A. Yap, P. H. M. Budzelaar, J. Am. Chem. Soc. 2002, 124, 12268-12274; d) D. Reardon, F. Conan, S. Gambarotta, G. Yap, Q. Wang, J. Am. Chem. Soc. 1999, 121, 9318-9325.

[5] a) C. Gunanathan, B. Gnanaprakasam, M. A. Iron, L. J. W. Shimon, D. Milstein, J. Am. Chem. Soc. 2010, 132, 14763-14765; b) K. L. Miller, B. N. Williams, D. Benitez, C. T. Carver, K. R. Ogilby, E. Tkatchouk, W. A. Goddard III, P. L. Diaconescu, J. Am. Chem. Soc. 2010, 132, 342-355 c) J. Cámpora, C. M. Pérez, A. Rodríguez-Delgado, A. M. Naz, P. Palma, E. Álvarez, Organometallics 2007, 26, 1104-1107; d) K. C. Jantunen, B. L. Scott, J. Hay, J. C. Gordon, J. L. Kiplinger, J. Am. Chem. Soc. 2006, 128, 6322-6323; e) X. Bei, D. C. Swenson, R. F. Jordan, Organometallics 1997, 16, 3282-3302; f) S. D. Gray, K. J. Weller, M. A. Bruck, P. M. Briggs, D. E. Wigley, J. Am. Chem. Soc. 1995, 117, 10678-10693; g) K. J. Weller, S. D. Gray, P. M. Briggs, D. E. Wigley, Organometallics 1995, 14, 55885597 ; h) P. Berno, S. Gambarotta, Organometallics 1994, 13, 2569 2571 ; i) L. M. Kobriger, A. K. McMullen, P. E. Fanwick, I. P. Rothwell, Polyhedron 1989, 8, 77-81.

[6] E. C. Constable, Polyhedron 2016, 103, 295-306.

[7] a) R. Arévalo, J. Pérez, L. Riera, Chem. Eur. J. 2015, 21, 3546-3549; b) R. Arévalo, J. Pérez, L. Riera, Inorg. Chem. 2013, 52, 6785-6787; c) M. A. Huertos, J. Pérez, L. Riera, J. Am. Chem. Soc. 2008, 130, 5662-5663; d) L. Cuesta, E. Hevia, D. Morales, J. Pérez, V. Riera, M. Seitz, D. Miguel, Organometallics 2005, 24, 1772-1775; e) L. Cuesta, E. Hevia, D. Morales, J. Pérez, V. Riera, E. Rodríguez, D. Miguel, Chem. Commun. 2005, 116117.

[8] E. Hevia, J. Pérez, V. Riera, D. Miguel, Organometallics 2002, 21, 19661974.

[9] The $3 \mathrm{M}, \mathbf{3 m}$ mixture is stable for 6 hours in THF- $\mathrm{d}_{8}$ below $233 \mathrm{~K}$ (it can be stored overnight in toluene at $253 \mathrm{~K}$ ). At room temperature, it produces 2 in 20 minutes in THF (or in 12 hours in toluene). The $3 \mathbf{M}: 3 \mathrm{~m}$ ratio was found to remain constant during the evolution towards 2 .
[10] C. K. McGill, A. Rappa, Adv. Heterocycl. Chem. 1988, 44, 1-79.

[11] P. S. Fier, J. S. Hartwig, Science 2013, 342, 956-960.

[12] C. S. Jr. Johnson, Prog. Nucl. Magn. Reson. Spectrosc. 1999, 34, 203256.

[13] K. Blaziak, W. Danikiewicz, M. Makosza, J. Am. Chem. Soc. 2016, DOI: 10.1021/jacs.5b13365

[14] K. G. Caulton, New J. Chem. 1994, 18, 25-41.

[15] Phen-bonded methyl group ${ }^{1} \mathrm{H}$ NMR integration against $\mathrm{C}_{6} \mathrm{Me}_{6}$ as internal standard afforded $\mathrm{t}_{1 / 2}$ of $1 \mathrm{~h}$ and $10 \mathrm{~h}$ and $40 \mathrm{~min}$ for $4 \mathrm{~m}-\mathrm{C} 2$ and $4 \mathrm{~m}-\mathrm{C} 4$ respectively. $\mathrm{t}_{1 / 2}$ of $\mathbf{4 M}-\mathrm{C} 2$ and $\mathbf{4 M}-\mathrm{C} 4$ were found to be longer than 3 days, with a faster disappearance of the $\mathbf{4 M - C 4}$ methyl signal (in comparison with $4 \mathrm{M}-\mathrm{C2}$ ).

[16] A. T. Balaban, D. C. Oniciu, A. R. Katrizky, Chem. Rev. 2004, 104, 27772812.

[17] D. R. Armstrong, C. M. M. Harris, A. R. Kennedy, J. J. Liggat, R. McLellan, R. E. Mulvey, M. D. T. Urquhart, S. D. Robertson, Chem. Eur. J. 2015, 21, 14410-14420.

[18] W. Kaim, Acc. Chem. Res. 1985, 18, 160-166.

[19] Compound 1 does not react with 3,4,7,8-tetramethyl-1,10phenanthroline ( $\mathrm{Me}_{4}$ phen) over 2 days at room temperature, nor does $\left[\operatorname{Re}(\mathrm{CO})_{3}\left(\mathrm{Me}_{4}\right.\right.$ phen $\left.)\left(\mathrm{PMe}_{3}\right)\right] \mathrm{OTf}$ with phen (see Figures S6-S9) demonstrating that the phen ligands are non-labile.

[20] P. H. M. Budzelaar, Eur. J. Inorg. Chem. 2012, 530-534.

[21] P. A. Lay, Inorg. Chem. 1984, 23, 4775-4777.

[22] a) M. Nakamura, E. Nakamura, N. Koga, K. Morokuma, J. Am. Chem Soc. 1993, 115, 11016-11017. In toluene-diethylether, in which we carried out the reaction, MeLi exists predominantly as tetramer: b) S. Desjardins, K. Flinois, H. Oulyadi, D. Davoust, C. Giessner-Prettre, O. Parisel, J. Maddaluno, Organometallics 2003, 22, 4090-4097. However, to keep the system manageable we employed the dimer in our calculations.

[23] Bulky secondary amides, such as $\mathrm{KN}\left(\mathrm{SiMe}_{3}\right)_{2}$, are usually considered non-nucleophilic due to their bulkiness, see: R. E. Mulvey, S. D Robertson, Angew. Chem. Int. Ed. 2013, 52, 11470-11487. Examples of nucleophilic behavior of $\mathrm{KN}\left(\mathrm{SiMe}_{3}\right)_{2}$, like the one reported here, are rare.

[24] Since the addition does not proceed via initial attack to Re followed by a Re-to-pyridine migration, intermolecular direct attack to the pyridine seems the most plausible pathway. However, as noticed by one reviewer, we are not excluding possibilities such as initial addition to one of the $\mathrm{CO}$ ligands.

[25] K. G. Caulton, Eur. J. Inorg. Chem. 2012, 435-443. 


\section{Entry for the Table of Contents}

Layout 1:

\section{COMMUNICATION}

Coordinated 1,10-phenanthroline: An excellent electrophile.

Coordinated 1,10-phenanthroline (phen) is usually considered a very inert ligand. However, phen in $\left[\mathrm{Re}(\right.$ phen $\left.)(\mathrm{CO})_{3}(\mathrm{PMe})_{3}\right] \mathrm{OTf}(\mathbf{1})$ undergoes the nucleophilic addition of internal (the deprotonated trimethylphosphane ligand (2)) and external $\left(\mathrm{KN}\left(\mathrm{SiMe}_{3}\right)_{2}(\mathbf{3} \mathbf{M}, \mathbf{3 m})\right.$ and MeLi (4M-C2)) nucleophiles under mild conditions.

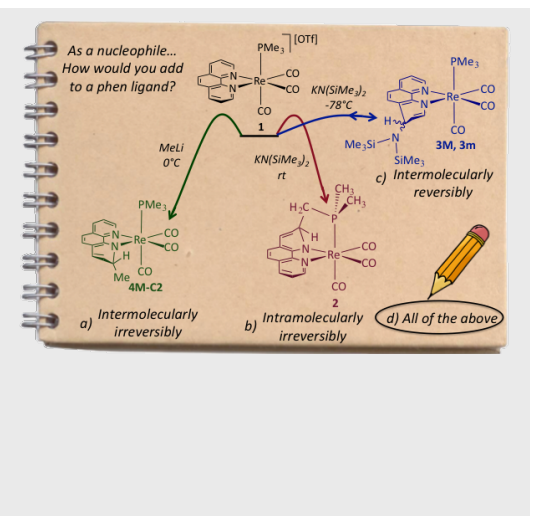

Rebeca Arévalo, M. Isabel Menéndez, Ramón López, Isabel Merino, Lucía Riera and Julio Pérez*

Page No. - Page No.

Nucleophilic Additions to Coordinated 1,10-phenanthroline: Intramolecular, Intermolecular, Reversible and Irreversible. 